АГАЗАДЕ Мирмехти Миркамил оглы - аспирант, ассистент кафедры теории и истории международных отношений Российского университета дружбы народов (117198, Россия, г. Москва, ул. Миклухо-Маклая, 10/2; aghazada53@gmail.com)

\title{
ИЗУЧЕНИЕ МЕЖДУНАРОДНЫХ ОТНОШЕНИЙ В АЗЕРБАЙДЖАНЕ
}

Аннотация. В статье рассматривается исторический аспект изучения международных отношений в Азербайджанской Республике (АР). Автор анализирует ключевые особенности азербайджанских исследовательских центров и подчеркивает ключевую роль университетов в изучении международной политики и международных отношений в АР. С другой стороны, автор вскрывает причины, почему в республике пока не удалось создать исследовательские центры, которые бы могли конкурировать с зарубежными по данной проблематике. В заключение автор выдвигает свои предложения по устранению этих причин.

Ключевые слова: международные отношения, Бакинский государственный университет, кафедра международных отношений, Университет ADA, Центр стратегических исследований

$\Pi$ осле обретения независимости в Азербайджане особое внимание стало уделяться изучению международных отношений как отдельной области гуманитарной науки. С этой целью в университетах были открыты новые факультеты и кафедры, а также исследовательские центры.

Обучение в университетах. В период, когда Азербайджан входил в состав Советского Союза, в Азербайджанской ССР не было учебных заведений, где преподавались бы дисциплины, связанные с международными отношениями. По этой причине в советское время азербайджанских дипломатов было очень мало [Гасанов 2013]. Однако в 1991 г. после восстановления государственной независимости возникла острая необходимость в профессионалах в области международных отношений и дипломатах для обеспечения участия АР в мировой политике. С этой целью в 1991 г. в Бакинском государственном университете (БГУ) был создан факультет международных отношений и международного права, на котором начала функционировать кафедра международных отношений ${ }^{1}$, которая вошла в историю азербайджанской науки как первая кафедра, изучающая международные отношения в Азербайджане [Həsənov 2005].

В 2011 г. факультет стал факультетом международных отношений и экономики. В настоящее время на факультете действуют 6 кафедр: 1) международных отношений; 2) дипломатии и современных интеграционных процессов; 3) экономики и управления; 4) мировой экономики; 5) математической экономики; 6) политологии и социологии ${ }^{2}$.

В целом, несмотря на то что в Азербайджане функционируют 51 государственный и частный университет, международные отношения преподаются лишь в нескольких из них: Университет $A D A$ (Азербайджанская дипломатическая академия), Академия государственного управления при Президенте АР, Бакинский славянский университет, университет Хазар, Азербайджанский университет языков, Азербайджанский государственный экономический университет, Нахичеванский государственный университет, Западно-Каспийский университет и Бакинский инженерный университет (см. табл. 1).

Среди этих университетов Университет $A D A$ отличается наличием внешних связей и экспертов в области международных отношений. Азербайджанская

1 Fakültənin tarixi. Доступ: http://iril.bsu.edu.az/az/content/fakltnin_tarixi\#.XFcy99szbDf (проверено 02.02.2019).

2 Fakültələr. Доступ: http://iril.bsu.edu.az/az/content/kafedralar_363\#.XFczrdszbDf (проверено 02.02.2019). 


\section{Таблица 1}

Высшие учебные заведения, где ведется преподавание международных отношений

\begin{tabular}{|c|c|c|c|c|}
\hline № & $\begin{array}{c}\text { Название } \\
\text { университета }\end{array}$ & \begin{tabular}{|c|} 
Год \\
основания
\end{tabular} & $\begin{array}{c}\text { Название факультетов } \\
\text { или кафедр }\end{array}$ & $\begin{array}{c}\text { Преподаваемые } \\
\text { дисциплины }\end{array}$ \\
\hline 1. & БГУ & 1919 & $\begin{array}{l}\text { факультет } \\
\text { международных } \\
\text { отношений и } \\
\text { Экономики } \\
\text { (созд. в } 1991 \text { г.) }\end{array}$ & $\begin{array}{l}\text { Теория международных } \\
\text { отношений, история } \\
\text { международных } \\
\text { отношений, дипломатия, } \\
\text { конфликтология и т.д. }\end{array}$ \\
\hline 2. & $\begin{array}{l}\text { Университет } \\
A D A\end{array}$ & 2006 & $\begin{array}{l}\text { школа общественных } \\
\text { и международных } \\
\text { отношений (созд. в } \\
2009 \text { г.) }\end{array}$ & $\begin{array}{l}\text { Дипломатия и между- } \\
\text { народные отношения, } \\
\text { государственное управ- } \\
\text { ление, политическая } \\
\text { система Азербайджана и т.д. }\end{array}$ \\
\hline 3. & $\begin{array}{l}\text { Академия } \\
\text { государственного } \\
\text { управления при } \\
\text { Президенте АР }\end{array}$ & 1999 & $\begin{array}{l}\text { факультет } \\
\text { Политического } \\
\text { управления } \\
\text { (созд. в } 1999 \text { г.) }\end{array}$ & $\begin{array}{l}\text { Международные } \\
\text { отношения и внешняя } \\
\text { политика, политология, } \\
\text { энергетическая дипломатия } \\
\text { и т.д. }\end{array}$ \\
\hline 4. & $\begin{array}{l}\text { Бакинский } \\
\text { славянский } \\
\text { университет }\end{array}$ & 2000 & $\begin{array}{l}\text { факультет } \\
\text { международных } \\
\text { отношений и } \\
\text { регионоведения } \\
\text { (созд. в 2004 г.) }\end{array}$ & $\begin{array}{l}\text { Конфликтология, } \\
\text { история международных } \\
\text { отношений, геополитика } \\
\text { и т.д. }\end{array}$ \\
\hline 5. & $\begin{array}{l}\text { Университет } \\
\text { Хазар }\end{array}$ & 1991 & $\begin{array}{l}\text { факультет } \\
\text { гуманитарных и } \\
\text { социальных наук } \\
\text { (созд. в } 1992 \text { г.) }\end{array}$ & $\begin{array}{l}\text { Теория и история между- } \\
\text { народных отношений, } \\
\text { политическая и экономи- } \\
\text { ческая география и т.д. }\end{array}$ \\
\hline 6. & $\begin{array}{l}\text { Азербайджанский } \\
\text { университет } \\
\text { языков }\end{array}$ & 1973 & $\begin{array}{l}\text { факультет } \\
\text { международных } \\
\text { отношений и } \\
\text { управления } \\
\text { (созд. в } 2001 \text { г.) }\end{array}$ & $\begin{array}{l}\text { Внешняя политика } \\
\text { Азербайджана, мировая } \\
\text { политика, международные } \\
\text { организации, современные } \\
\text { интеграционные процессы } \\
\text { и т.д. }\end{array}$ \\
\hline 7. & $\begin{array}{l}\text { Азербайджанский } \\
\text { государственный } \\
\text { экономический } \\
\text { университет }\end{array}$ & 1930 & $\begin{array}{l}\text { кафедра } \\
\text { международных } \\
\text { отношений } \\
\text { (созд. в } 2005 \text { г.) }\end{array}$ & $\begin{array}{l}\text { Современные между- } \\
\text { народные отношения, } \\
\text { основы дипломатии, } \\
\text { дипломатический протокол } \\
\text { и т.д. }\end{array}$ \\
\hline 8. & $\begin{array}{l}\text { Нахичеванский } \\
\text { государственный } \\
\text { университет }\end{array}$ & 1967 & $\begin{array}{l}\text { факультет } \\
\text { международных } \\
\text { отношений и } \\
\text { иностранных языков } \\
\text { (созд. в 2006 г.) }\end{array}$ & $\begin{array}{l}\text { История международных } \\
\text { отношений, дипломатия, } \\
\text { внешняя политика } \\
\text { Азербайджана и т.д. }\end{array}$ \\
\hline 9. & $\begin{array}{l}\text { Западно- } \\
\text { Каспийский } \\
\text { университет }\end{array}$ & 1991 & $\begin{array}{l}\text { кафедра } \\
\text { политических наук } \\
\text { (созд. в } 1991 \text { г.) }\end{array}$ & $\begin{array}{l}\text { Теория и история } \\
\text { международных } \\
\text { отношений, внешняя } \\
\text { политика Азербайджана и } \\
\text { зарубежных стран и т.д. }\end{array}$ \\
\hline 10 & $\begin{array}{l}\text { Бакинский } \\
\text { инженерный } \\
\text { университет }\end{array}$ & 2016 & $\begin{array}{l}\text { кафедра } \\
\text { международных } \\
\text { отношений } \\
\text { (созд. в } 2017 \text { г.) }\end{array}$ & $\begin{array}{l}\text { Внешняя политика } \\
\text { Азербайджана и } \\
\text { зарубежных стран, } \\
\text { мировая политика, основы } \\
\text { дипломатии и т.д. }\end{array}$ \\
\hline
\end{tabular}


дипломатическая академия, основанная при МИД АР в 2006 г., была переименована в Университет $A D A$ в 2014 г. после объединения с Университетом информационных технологий AP1. Основная задача университета, в котором обучаются студенты и работают преподаватели и профессора из 46 стран мира, - подготовить политиков, дипломатов и специалистов в области внешней политики, связей с общественностью, бизнеса, информационных технологий и системотехники. Что касается заявленной миссии университета, то это: 1) подготовка будущих лидеров и ответственных граждан; 2) развитие у студентов таких навыков, как командная работа, аналитическое и критическое мышление с использованием интерактивной методологии; 3) внедрение современной системы образования, которая сочетает в себе теорию и практику и соответствует международным стандартам; 4) содействие развитию науки и исследованиям в сфере образования.

БГУ является первым современным университетом не только в Азербайджане, но и на всем мусульманском Востоке. Университет был основан в 1919 г. парламентом Азербайджанской Демократической Республики. В настоящее время на 17 факультетах университета обучаются около 20 тыс. студентов по 60 специальностям в степени бакалавра, по 197 - в магистратуре и по 70 - в докторантуре. Обучение ведется на трех языках - азербайджанском, русском и английском. В университете обучаются около 1000 иностранных студентов изо всех стран мира. В учебный процесс вовлечены около 1500 профессоров и преподавателей ${ }^{2}$.

Во время учебы по специальности «Международные отношения» студенты этих университетов изучают следующие ключевые аспекты:

1) историю международных отношений и внешней политики;

2) различные теории международных отношений;

3) методы, используемые при изучении истории международных отношений;

4) глобальные проблемы человечества и пути их решения;

5) определение места Азербайджана в экономической и политической системе современного мира;

6) условия формирования современных интеграционных процессов, теоретические и практические аспекты интеграционных процессов и участия Азербайджанской Республики в процессе глобализации и др.

Регион, который ученые-международники изучают в Азербайджане, это, в первую очередь, пространство СНГ. Связано это с тем, что Азербайджан имеет тесное сотрудничество со странами СНГ, а также с влиянием российской научной школы на азербайджанскую. Помимо СНГ, наиболее изучаемыми объектами исследования являются Ближний Восток и Западная Европа. Основными западными теориями, которые ученые-международники используют для анализа международных отношений, являются реализм, либерализм, политический реализм, политический либерализм, конструктивизм и др.

Несмотря на преподавание в университетах дисциплин по международным отношениям, на базе азербайджанских университетов еще не успели сформироваться научные школы со своими авторитетами. Только Университет $A D A$ отличается от других своей уникальной системой обучения и преподавания. Основными преимуществами Университета $A D A$ являются совместные программы обучения с зарубежными вузами и прямая поддержка со стороны МИДа АР.

Исследовательские центры. Кроме университетов, существуют ряд исследова-

\footnotetext{
1 ADA University. Доступ: https://www.ada.edu.az/en/about/ada-university (проверено 02.02.2019).

2 BDU-da təhsil. Доступ: http://bsu.edu.az/az/content/bduda_thsil (проверено 02.02.2019).
} 
тельских центров, которые занимаются исследованием международных отношений и политики. Среди них можно выделить Центр стратегических исследований при Президенте АР ( $S A M)$, который отличался мощной финансовой поддержкой власти. Основной целью Центра, который функционировал в 20072018 гг., являлось содействие развитию различных сфер жизни страны, включая научные исследования в области геополитики, безопасности, государственного строительства, регионального развития, решения существующих проблем, а также обеспечение высших органов государственной власти Азербайджанской Республики прогнозно-аналитической информацией ${ }^{1}$.

За время своего существования $S A M$ подготовил 892 справочника и отчета по международным отношениям, вопросам внутренней, внешней и экономической политики для соответствующих государственных структур Азербайджанской Республики. В местных и зарубежных СМИ были опубликованы 1078 статей о региональных и международных процессах, были проведены более 480 интервью. В то же время $S A M$ совместно с местными и международными партнерами провел около 280 мероприятий в Азербайджане и 22 - в зарубежных странах, посвященных глобальным вызовам современности и стратегическим аспектам международных отношений. Среди них 106 международных конференций, 118 круглых столов и дискуссий, 23 презентации книг и 30 лекций ${ }^{2}$.

Однако в начале января 2019 г. по указу президента АР деятельность $S A M$ была прекращена.

На сегодняшний день среди основных исследовательских центров, занимающихся различными проблемами международных отношений в Азербайджане, можно отметить следующие.

1. Исследовательский центр «Атлас». Создан в 2005 г. независимым политологом Эльханом Шахиноглу. Центр изучает вопросы региональной безопасности, в т.ч. отношения с ближайшими соседями Азербайджана и международными организациями, а также проводит мониторинг переговорного процесса по урегулированию Нагорно-Карабахского конфликта.

2. Центр кавказских этносоциальных исследований (QESAM $\left.{ }^{3}\right)$. Этот центр, созданный в 2006 г., готовит отчеты, соответствующие стратегическим интересам Азербайджана. Основная миссия центра - осуществление прогнозов на основе процессов, происходящих в регионе и в мире.

3. Исследовательский иентр «Глобал». Основная цель центра, созданного в 2013 г., состоит в том, чтобы изучать роль и место Азербайджана в мировой экономике, и также донести точку зрения АР по поводу территориального вопроса между Арменией и Азербайджаном до международного сообщества.

4. Исследовательский центр «Карабах». Центр был основан в 2013 г. совместными усилиями Академии государственного управления при Президенте АР и азербайджанской общины Нагорно-Карабахского региона АР. Основной целью открытия центра является подготовка молодых специалистов для изучения проблем Карабаха, а также приложение усилий для мирного урегулирования карабахского конфликта.

5. Каспийский энергетический исследовательский центр. Основным направлением деятельности центра, созданного при университете Хазар, является изучение энергетических ресурсов Азербайджана, мониторинг и исследование деятельности международных энергетических компаний в Азербайджане. Центр

\footnotetext{
1 About SAM. Доступ: http://sam.az/articles/category/about/en (проверено 02.02.2019).

2 Annual Reports. Доступ: http://sam.az/articles/category/year/ (проверено 02.02.2019).

3 Qesam haqqinda. Доступ: http://qesam.org/ust/1/1.htm (проверено 02.02.2019).
} 
также занимается академической и образовательной деятельностью и признан одним из лучших независимых экспертных институтов в Азербайджане.

6. Исследовательский центр «Кавказ» $\left(Q A F A M^{1}\right)$. Основное внимание центр уделяет изучению отношений между странами Южного Кавказа, подготовке отчетов в рамках интересов АР и анализу возможного влияния других стран на Кавказский регион.

7. Кавказский Центр международных отношений и стратегических исследований 2 . Центр, основанный в 2006 г., отличается от других исследовательских центров широтой сфер своей деятельности. Так, после его основания к работе в центре были привлечены лучшие азербайджанские специалисты, получившие образование в американских и европейских вузах. Центр изучает не только Кавказский регион, но и Европу, Африку, Америку, Ближний Восток, Дальний Восток и Центральную Азию. В рамках деятельности центра особое место занимает изучение и анализ этнических конфликтов.

В целом, основным направлением всех этих центров является исследование армяно-азербайджанского Нагорно-Карабахского конфликта и оказание помощи властям в информационном противостоянии с Арменией.

Тем не менее следует отметить, что, несмотря на их связи с государственными органами, они, в отличие от университетов, не финансируются государством, а либо спонсируются бизнесменами, либо осуществляют самофинансирование. По этой причине в некоторых центрах даже нет официальных сайтов.

Будущее науки о международных отношениях. К сожалению, нужно отметить, что на сегодняшний день изучение международных отношений и международной политики как науки в Азербайджане значительно отстает от других гуманитарных специальностей. Некоторые эксперты указывают на то, что главной причиной данного явления является его новизна. С другой стороны, использование одного и того же учебного плана ежегодно в некоторых университетах, где преподаются международные отношения, рассматривается как препятствие для развития этой области знания. Тем не менее следует отметить, что, благодаря Университету $A D A$, в последние годы число специалистов в этой сфере выросло. Несмотря на то что развитие изучения международных отношений отмечается только в одном университете, это дает надежду, что примеру $A D A$ последуют и другие высшие учебные заведения.

Заключение. Подводя итоги исследования проблем изучения международных отношений в АР, следует отметить, что в настоящее время их уровень в Азербайджане отстает от общемирового. Этому есть несколько причин. Прежде всего, следует отметить, что, хотя Министерство образования АР время от времени предпринимает шаги по повышению качества образования в университетах, к сожалению, система образования в стране еще не полностью сформирована. Это отрицательно влияет на другие области исследований, а также затрудняет изучение международных отношений в целом.

С другой стороны, несмотря на то что в университетах преподают различные дисциплины по данной специальности, тем не менее студенты изучают только теоретическую часть и испытывают трудности на практике. Другая причина состоит в том, что международные отношения не изучаются как наука нигде, кроме университетов. В связи с этим отсутствие необходимых научно-исследовательских и политических центров является еще одной причиной, препятствующей появлению глубоких исследований по данной теме. Чтобы преодолеть все эти препятствия и углубить изучение международных отношений, должны

\footnotetext{
${ }^{1}$ Haqqımızda. Доступ: http://www.qafam.org/haqqimizda.php (проверено 02.02.2019).

2 Haqqımızda. Доступ: http://www.qafsam.org/page/2/az (проверено 02.02.2019).
} 
быть созданы новые научно-исследовательские и политические центры, которые будут сотрудничать с университетами, официальными государственными органами, а университеты при подготовке специалистов должны использовать общемировые практики. Также особое внимание следует уделить сотрудничеству с зарубежными университетами. Особенно большую роль в этом играет сотрудничество с российскими вузами, которое должно развиваться. Так как за последние два столетия Россия и Азербайджан по многим вопросам проживали одну и ту же судьбу, российские ученые сыграли большую роль в развитии азербайджанской науки, а азербайджанские ученые - в российской. Поэтому приглашение специалистов из ведущих российских вузов в азербайджанские вузы и использование их опыта может дать толчок развитию изучения международных отношений в Азербайджане.

Статья подготовлена в рамках НИР РУДН «Незападные теории международных отношений. Азиатские, африканские и латиноамериканские концепции мироустройства».

\title{
Список литературы
}

Гасанов А.М. 2013. Современные международные отношения и внешняя политика Азербайджана. Баку: Zordabi LTD MMC. 990 с.

Həsənov Ә. 2005. Müasir beynalxalq münasibətlar va Azərbaycanın xarici siyasəti. Dərslik. Bak1: Azərbaycan nəşriyyatı. 631 p.

\section{THE STUDY OF INTERNATIONAL RELATIONS IN AZERBAIJAN}

\begin{abstract}
The article is devoted to the problems of studying international relations in the Republic of Azerbaijan. First of all, the author considers the historical aspect of studying this sphere in Azerbaijan, and then analyzes the key features of the Azerbaijani research centers. After gaining independence, Azerbaijan began to take a unique place in the South Caucasus Region and sought to take its place in the international political arena. To achieve the goals, it was necessary to train specialists in the field of international relations, find out how the system of international relations works, what are its principles and working mechanisms. The training of such specialists is the responsibility of universities and research centers. Also during the analysis, the key role of universities in the development of studying the field of international relations in the Republic of Azerbaijan was emphasized. On the other hand, the reasons for which it was not possible to create centers in Azerbaijan that could compete with foreign ones in the field of international relations were explained. In conclusion, the author puts forward his proposals and theses to eliminate these causes.
\end{abstract}

Keywords: international relations, Baku State University, Chair of International Relations, ADA University, SAM 